\title{
Digital Transformation in Higher Education: A Framework for Maturity Assessment
}

\author{
Adam Marks ${ }^{1}$, Maytha AL-Ali ${ }^{2}$, Reem Atassi ${ }^{3}$, Abedallah Zaid Abualkishik ${ }^{4}$, Yacine Rezgui ${ }^{5}$ \\ American University in the Emirates ${ }^{1,3,4}$ \\ Zayed University, Dubai, $\mathrm{UAE}^{2}$ \\ University of Cardiff, Cardiff, $\mathrm{UK}^{5}$
}

\begin{abstract}
Literature in digital transformation maturity is scarce. Digital transformation in higher education, especially after COVID-19 is seen as inevitable. This research explores digital transformation maturity and challenges within Higher Education. The significance of this study stems from the role digital transformation plays in today's knowledge economy. This study proposes a new framework based on Deloitte's 2019 digital transformation assessment framework with Petkovic 2014 mega and major higher education process mapping. The study triangulates the findings of multiple research instruments, including survey, interviews, case study, and direct observation. The research findings show a significant variance between the respondents' perception of digital transformations maturity levels, and the core requirements of digital transformation maturity. The findings also show the lack of holistic vision, digital transformation competency, and data structure and processing as the leading challenges of digital transformation.
\end{abstract} 19

Keywords-Digital transformation; higher education; COVID-

\section{INTRODUCTION}

Organizations today are operating in a massive, digitally connected world, and their stakeholders expect seamless and personalized digital services [2], and [9]. Producing and acquiring knowledge has a great importance today. The success of organizations and nations highly depends on producing and using information successfully. The increased use and production of knowledge places organizations into a necessary digital transformation. This digital transformation impacts the core components of an organization - from its operating model to its infrastructure. Organizations usually do not transform by choice, more often when they fail to evolve and keep up with market changes and technology disruptions [24].

Terms like digitization, digitalization, and digital transformation can be confusing, especially if used interchangeably, however they refer to distinct concepts. While digitization is concerned with transforming analog objects into digital representations, digitalization is concerned with improving processes by use of digitized data and programs, also known as automation [10]. Digital transformation is concerned with transforming organizational processes; build new competencies and models through digital technologies in a profound and strategic way [12]. Digital transformation refers to an organizational change realized by means of digital technologies and business models with the aim to improve organization's operational performance. It involves much more than implementing a well-chosen technology solution, it is a close alignment between information technology and business processes that will lead to a substantial outcome for the organization, keeping in mind organizational readiness, change management, and managing key stakeholders [15].

The author in [4] states "Digital transformation is not only the transformation of tool, technologies and process but it is transformation of entire business model. It changes the way a business operates and interacts within itself and with external world. Business transformation is a change in mind set that business is evolving faster than we are adapting”. Digital transformation should have a strategic objective defined in an operational architecture with business use cases.

Similar to other industries, higher education institutions need to make informed decisions, and at times quick decisions to streamline operations, understand their customers, service delivery, product development, asset utilization or other operational areas. Data should be used to discover hidden patterns, and underlying performance in specific areas, and influence decisions that yield maximum impact for the organization. Legacy systems can result in significant cost and strain budgets. Moreover, threats to higher institutions, both online and on campus, present an urgent need for security and intelligence about students and staff more than ever before. Those challenges cannot be addressed using manual forms and processes. Higher education institutions today must integrate digital technologies into their business to a much greater extent than before [12] and [15].

The impact and magnitude of the COVID-19 pandemic forced many sectors to attempt to do business online. Education and higher education institutions across the globe had to make quick and important digital transformation adjustments to sustain operations. Questions about course delivery, virtual classrooms, seats, capacity, conducting exams and assessments, academic integrity, use of web cams, capacity and quality of video conferencing, and many other questions were raised. Many universities signed up with Zoom, MS Teams, Respondus, and other software systems to sustain operations.

Literature in digital transformation maturity and challenges, specifically within higher education, and more specifically within developing nations is scarce. This study aims to address those identified gaps. Given the importance of higher education in today's information society and knowledge economy, this study is significant to higher education institutions, as well as to other stakeholders involved in the hierarchys of higher education, including students, educators, researchers, institutions, and government agencies. Digital transformation 
in higher education, especially after COVID-19 is seen as inevitable not only to compete, but also to survive and sustain key operations.

This research explores digital transformation maturity and challenges within United Arab Emirates "UAE", one of the advanced developing nations in terms of IT infrastructure and digital transformation plans. The significance of the study does not only stem from the critical role higher education is responsible in educating and training future leaders, workers, and citizens; but also from the key role digital transformation plays in today's knowledge economy, which became more evident after the COVID-19 pandemic.

The next section of this paper presents some of the literature related to the main topic of this study, followed by the research methodology, the discussion, conclusion, and recommendation.

\section{RELATED WORK}

Digital transformation is a key element of the 4 th industrial revolution. The author in [20] describes the emergence of the fourth industrial revolution by linking three fundamental factors. These are: "Speed: New technologies that are connected to each other and are very versatile move quickly at an exponential speed, triggering each other. Width and Depth: Digitization speeds up the industry 4.0. However, the increase in technology diversity in the industry has brought about the change. System Impact: Industry 4.0 is expected to undergo a total change as digital industries, companies, and even countries".

The author in [13] breaks digital transformation into three attributes: creating value, optimizing the processes that execute a vision of customer experiences, and building foundational capabilities that support the entire structure. Fig. 1 shows the three attributes of digital transformation with more details.

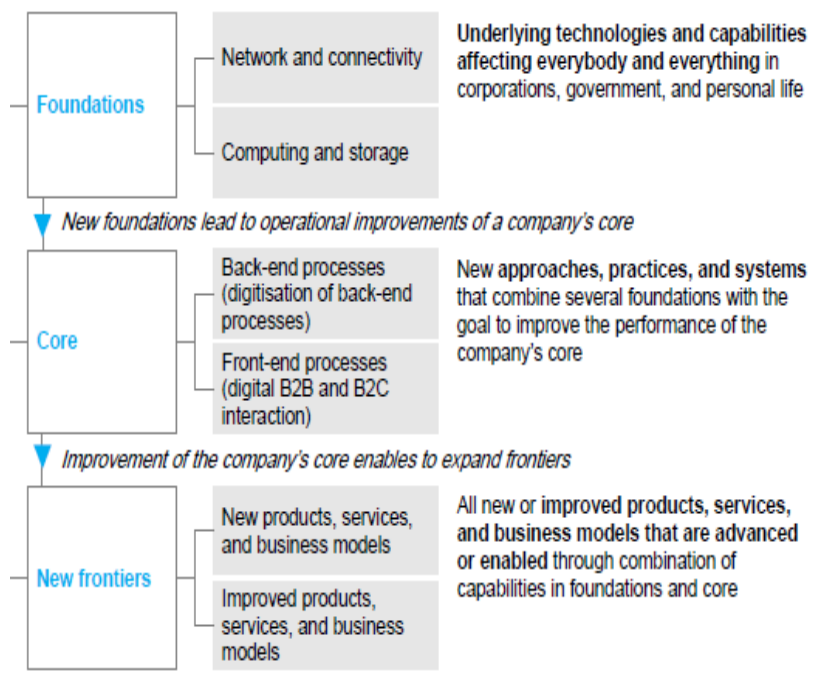

Fig. 1. Digital Transformation Attributes - [13].
There are several reasons why organizations undergo digital transformation; however, the main reasons are related to the issues of competitive advantage and survival. Digital transformation of an organization represents an objective process capable at responding to disruption in critical functions and changing organizations environments [21], and [23]. As in other industries, four elements are driving digital transformation in education: customer experience, competitiveness, profitability, and agility [11].

The impact of digital transformation transcends technology. Through the process of digital transformation, organizations use multiple new digital technologies, with the intent to achieve superior performance and sustained competitive advantage. In such way, they transform different dimensions of business, such as the business model, the customer experience and operations, and simultaneously impacting people and networks [13].

The author in [6] presents six dimensions to digital transformation, they are: Established and accepted organizational digital strategy, Organized agile, and adaptable collaborative processes in modern business models; Complete automation of business processes; Detailed analysis and research of customers' decision making; Information technology supporting all organizational business processes; Usable and relevant data, use of data analytics as a basis for decision making in line with the organization's goals and strategy.

The author in [3] talks about four dimensions of digital transformation, namely "the purpose", "degree of strategy", "speed of strategy", and "the value source". Table I shows those dimensions in more details.

Fig. 2 outlines the main sectors that have been disrupted by digital transformation. Public Sector related entities, including education, are being disrupted now by digital transformation. The opportunity for the Public Sector is to learn from the previous experiences of other sectors.

TABLE I. DIGITAL TRANSFORMATION: DIMENSIONS, ISSUES, AND IMPLICATIONS [3]

\begin{tabular}{|l|l|l|}
\hline $\begin{array}{l}\text { Dimension of Digital } \\
\text { Transformation }\end{array}$ & $\begin{array}{l}\text { Questions for Manager } \\
\text { (Strategy, organization, and } \\
\text { Business Models) }\end{array}$ & Main Topics \\
\hline $\begin{array}{l}\text { The purpose of } \\
\text { digitation strategy }\end{array}$ & $\begin{array}{l}\text { Which analytical methods will } \\
\text { be selected in the company } \\
\text { What are the spaces for } \\
\text { development and value creation }\end{array}$ & $\begin{array}{l}\text { Determining and } \\
\text { analyzing the value } \\
\text { creation space }\end{array}$ \\
\hline $\begin{array}{l}\text { Degree of } \\
\text { digitization strategy }\end{array}$ & $\begin{array}{l}\text { What is the relative importance } \\
\text { of platforms? } \\
\text { What kind of typology? } \\
\text { Which governance structure } \\
\text { promotes innovation? }\end{array}$ & $\begin{array}{l}\text { Defining and } \\
\text { analyzing the idea } \\
\text { of creating new } \\
\text { platforms }\end{array}$ \\
\hline $\begin{array}{l}\text { The speed of } \\
\text { digitization strategy }\end{array}$ & How to define innovation offers & $\begin{array}{l}\text { Fast and systematic } \\
\text { phenomena }\end{array}$ \\
\hline $\begin{array}{l}\text { Value sources, } \\
\text { creation based on } \\
\text { digital strategy }\end{array}$ & $\begin{array}{l}\text { What are the sources of value } \\
\text { creation in digital space }\end{array}$ & $\begin{array}{l}\text { Define the } \\
\text { proposed values of } \\
\text { the digital space }\end{array}$ \\
\hline
\end{tabular}




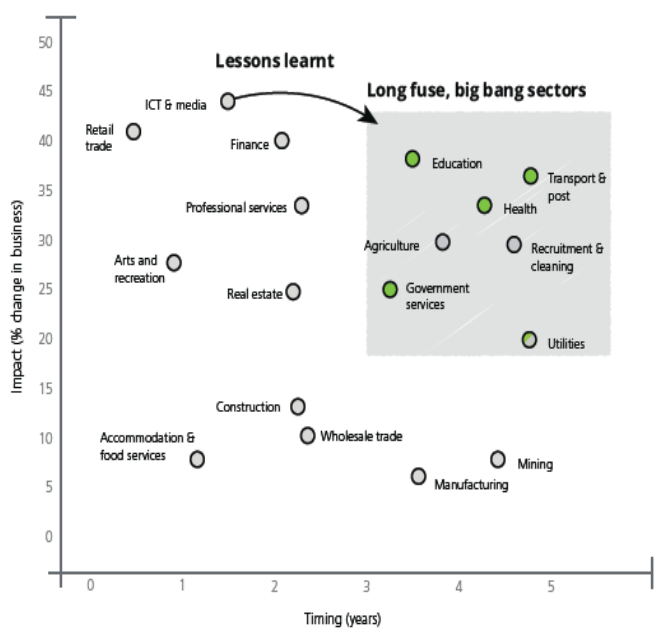

Fig. 2. Sectors affected by Digital Transformation - [5].

In the Middle East and North Africa "MENA" region, the trends of information and communications technologies (ICT) are very diverse due to different levels of development both between and within countries. This gap can be attributed to different aspects including infrastructure, economic conditions, job market, and lack of adequate governance. Nevertheless, nearly all countries in the region are pursuing policies supporting digitalization to further development.

Countries - such as the United Arab Emirates (UAE), and Saudi Arabia, are well equipped for further technological development [8]. However, the National ICT Index still shows that those countries still lag behind other developed economies in terms of Digital Government capabilities [13] and [17].

To address their own economic, social and environmental challenges, several governments in the MENA region have launched national transformation plans with a focus on enabling ICT and Digital Transformation technologies. Integrating digital technologies to develop smarter cities and become smarter nations is a key outcome of their national visions [13] and [15].

Globally, higher education digital transformation is highly influenced by government policies and institutional development strategies [26]. The aim of the digital transformation process in higher education is to redefine educational services and redevelop operational processes. This can be achieved using three possible approaches. The first approach involves service-first transformation. It focuses on changing and redefining services before making key improvements and changes to operations. The second approach is the operation-first transformation. In this approach, the higher education institution identifies new and amends current digital processes, activities and operations. The third approach is service-operation combination, involves integrated transformation through systematic interrelation of both previous approaches [19].

As shown in Table II, [18] maps higher education business processes into four hierarchical levels: mega processes, major processes, sub-processes, activities and tasks. The mega processes include the learning and teaching process, the research process, the enabling process, and the planning and governance process.

The author in [5] presents a Digital Maturity Assessment Framework, using five key criteria:

- Does the organization have the right vision and strategy for digital, and the leadership, communications and focus required to support this vision?

- Does the organization have the right talent, skills and knowledge to support its vision, products, and services?

- Does the organization have the right processes, controls and digital technologies to support the operations of the organization?

- Does the organization have the right technologies and infrastructure as well as the ability to develop, manage and deliver?

- Does the organization have the right approach to understanding and communicating with its customers to succeed in a digital environment? [12]

The author in [16] study provide a similar presentation of higher education business processes and example of new digital trends, as shown in Table III.

Fig. 3 visualizes results from Gartner's 2017 CIO Survey, shows where higher education intuitions are in terms of digital transformation. Organizational mind-set is what separates the No digital initiative institutions from those with Desire/Ambition. This transformation requires a framework that is effectively communicated to key stakeholders and decision makers. If employed correctly, digital transformation can play a major role in today's higher education including in the areas of admission tracking, enrollment optimization, and academic advising [7].

TABLE II. OVERVIEW OF MEgA AND MAJOR Processes IN Higher EDUCATION INSTITUTIONS [18]

\begin{tabular}{|l|l|}
\hline Learning and Teaching Process & Research Process \\
\hline Study program accreditation & Research planning \\
\hline $\begin{array}{l}\text { Teaching process preparation and } \\
\text { realization }\end{array}$ & Research preparation \\
\hline $\begin{array}{l}\text { Teaching process outcomes } \\
\text { monitoring }\end{array}$ & Research conduct \\
\hline Teaching process assessment & Research outcomes monitoring \\
\hline $\begin{array}{l}\text { Student and teacher mobility } \\
\text { realization }\end{array}$ & Research evaluation \\
\hline Enabling Process & Planning and Governance Process \\
\hline Student administration services & Organization management services \\
\hline $\begin{array}{l}\text { Library services } \\
\text { Staff provision and development } \\
\text { services }\end{array}$ & $\begin{array}{l}\text { Change and business process } \\
\text { management }\end{array}$ \\
\hline Finance and accounting services \\
\hline $\begin{array}{l}\text { Marketing, sales, and distribution } \\
\text { services }\end{array}$ & Budget ad funds planning \\
\hline Procurement services & Performance assessment \\
\hline
\end{tabular}


TABLE III. CATEGORIES OF EDUCATIONAL SERVICES AND NEW DigitAL TRENDS [16]

\begin{tabular}{|l|l|}
\hline $\begin{array}{l}\text { Categories of educational } \\
\text { services }\end{array}$ & Examples of new digital trends \\
\hline Administration & $\begin{array}{l}\text { Application for enrollments, enrollments for } \\
\text { exams, grade generation, class schedule }\end{array}$ \\
\hline Communication & $\begin{array}{l}\text { Collaboration platforms, online } \\
\text { communication }\end{array}$ \\
\hline $\begin{array}{l}\text { Teaching and preparing } \\
\text { lessons }\end{array}$ & Electronic books, online learning resources \\
\hline Teaching and learning & Online learning \\
\hline Reviews and examinations & Reviewing test and exams, Exam grading \\
\hline $\begin{array}{l}\text { Less mature } \\
11 \%\end{array} \quad 27 \%$ & $13 \%$ \\
\hline $\begin{array}{l}\text { No digital initiative } \\
\text { Desire/Ambition } \\
\text { Designing } \\
\text { Delivering } \\
\text { Scaling } \\
\text { Harvesting }\end{array}$ \\
\hline
\end{tabular}

Fig. 3. Digital Transformation Maturity in Higher Education- Source: [7].

The literature shows that digital transformation is usually faced with a number of challenges. More often than not, those challenges are not listed in any specific order based on criticality, and they are not attached to a specific industry. Challenges reported include: the changing customer experience/expectations, resistance to change, resistance to technology, lack of leadership support, lack of competency and digital transformation skills, failing or poor analytics, lagging and legacy business models and systems, poor planning, misalignment with business strategy, technology and data challenges, lack of clear vision, and digital literacy of stakeholders [18], [14], and [11].

If implemented correctly, digital transformation tools and technologies such as Artificial Intelligence (AI), Internet of Things (IoT), big data, block chain, social analytics, and cloud services can enhance and change educational system practices, especially in a world where students are constantly interacting with technology in all other aspects of their everyday lives, digital transformation clearly offers opportunities for student engagement that are not always available in the fixed environment of the classroom [1], and [27].

The author in [22] discuss four ways where digital transformation may change how education looks in the future, namely smart content, differentiated and personalized learning, global and remote learning, and administrative efficiencies.

In the area of "Smart Content", digital transformation can be attained through e-books, new learning platforms, virtual content such as video lectures and conferences, electronic curricula, distributed educative information across devices. Similarly, in the area of "Differentiated and Personalized Learning", digital transformation can be attained through personalized electronic tutoring customized to the learning styles and particular needs of the student. The traditional curriculum is designed to suit as many students as possible. For students in the top 10 percent and the bottom 10 percent, AI for example can be used to provide testing and feedback to those students to give them challenges they are ready for, identify gaps in knowledge and re-direct them to new topics when appropriate.

In the area of "Global and Remote Learning", digital transformation can facilitate learning from anywhere and at any time. Furthermore, it can be used to support students with homework and exam preparation remotely with advanced tutoring and study programs.

Last, in the area of "Administrative Efficiencies", digital transformation can support higher education to shift from wondering about the future into predicting, forecasting, and shaping the future; making proactive and informed decisions and taking action based on that information. Digital transformation can support universities in using conventional and unconventional (unstructured), internal and external data to discover hidden patterns underlying performance in different areas, track admissions, optimize enrolment, manage grants, enhance academic advising etc. Digital transformation can help higher education institutions to know what is happening (descriptive analytics), what is likely to happen in the future (predictive analytics) and to examine trends, causes and likely forecasts and use that information to make decisions (prescriptive analytics) [22], and [25].

\section{Methodology}

While the importance of digital transformation is recognized, data about digital transformation maturity and challenges is scarce, especially in developing nations, and specifically within higher education. This study explores digital transformation maturity level in Higher Education Institutions in UAE higher education. The study uses a new framework that is based on the Petkovic's 2014 mega and major processes mapping, and [12] maturity assessment framework. The researchers believe that Petkovic provides a balanced and comprehensive classification of higher education business processes using four hierarchical levels: mega processes, major processes, sub-processes, activities and tasks. Unlike other classifications, the Petkovic's classification does not contain overlapping, ambiguous, and repetitive processes. The researchers also believe that digital transformation maturity criteria listed in the maturity assessment framework by [12] are comprehensive, tangible, easy to understand and reflective. Based on the above, the combination of both models provides a good starting point for higher education institution to assess their digital transformation maturity level, and identify areas that need improvements. The proposed framework in this study is flexible, customizable, and can support further more detailed analysis as required. The study examines public and private higher education institutions in the UAE. It ranks the criticality of digital transformation challenges using identified pattern codes such as the regulatory and business environment, IT infrastructure, data governance, affordability and budget constraints, personnel competency and IT skills, etc. We consider that the problem identification and related key issues are very important in order to achieve successful implementation of digital transformation.

The goal of this study is achieved throughout several objectives, beginning from the literature study of the state of the art, continuing with the wide-distributed survey, in-depth semi-structured interviews, direct observation of the 
researchers, and case study. The literature study provided the possibility of identifying and analyzing trends related to the topic, while the survey, interviews, direct observation, and case study provided the possibility of identification and analysis of trends in the field of digital transformation at the national level in public and private higher education institutions. This study is a phenomenological research to determine the views of IT director and senior academicians on the maturity and challenges of digital transformation. Phenomenological researches may not reveal generalizable situations, but they can provide examples, explanations and experiences that will help to a phenomenon identified and understood better [25], and [15].

The survey was conducted in both public and private higher education institutions, targeting IT directors, chief information officers, and senior academicians concerned with digital transformation. The survey was sent to 61 individuals. Response was received from 52. The questionnaire design and construction consist of 15 Likert Scale closed-ended multiplechoice-five-pointer questions. Respondents were required to complete the questionnaire indicating the extent to which they agree or disagree with the questions. A room for comments for each question was also available. The survey questions were divided into three sections; the first section measures the respondent's view on the institution's level of digital transformation maturity; the second section verifies the existence/non-existence of key elements of digital transformation maturity; and the third section ask about the respondents rating of the challenges faced.

Six in-depth, semi-structured interviews were held with IT directors, and another four interviews were held with senior academic administrators to gain deeper understanding of expected value and the challenges faced during digital transformation; direct observation was used to verify what people do, rather than what people say they do, lastly, a case study was conducted at one of the public universities to validate and triangulate the results of the survey, direct observation, and the interviews.

The importance and the rationale of this research lie in the identification and analyses of the readiness of higher education institutions in the UAE to embrace a meaningful and mature level of digital transformation in higher education academic processes post COVID-19.

The research results can be used as an important input to the design of new academic processes that would be more effective, aligned, efficient, and cost-effective. Moreover, this study points to the key challenges faced by higher education institutions in the UAE in achieving mature digital transformation, turning data into a valuable asset that could be used for prescriptive, corrective and predictive decisionmaking, using a proposed framework to measure digital transformation maturity, and pinpoint areas of concern and areas of strength. The research also provides the practitioners from the field of digital technologies with the information and knowledge related to their potential market and the related trends.

\section{DISCUSSION}

In this section, we present the findings of this study, responding directly to the two key research questions.

What is the level of digital transformation maturity in the examined UAE higher education institutions?

The data collected in this study shows a significant variance between digital transformations maturity level perception reported by the respondents, and the core requirements of digital transformation maturity. While more than 80 percent of the examined institutions reported a digital transformation maturity level between "delivering or harvesting" as seen in Fig. 4, none of them had a comprehensive digital transformation plan.

A few reported a list of digital transformation initiatives. However, those list of initiatives were more aligned with automation not digital transformation, and they were mostly initiated to comply with external regulatory requirements by the Telecommunication Regulatory Authority TRA. In almost all cases, digital transformation initiatives had no connection to a return on investment, gained value, or a real transformation of a business process. The great majority of cases were concerned with the automation of electronic forms, adding workflow and approvals. None of the initiatives reported was concerned with analytics, machine learning, artificial intelligence, big data and other more-advanced digital transformation technologies.

As shown in Table IV, based on proposed higher education digital transformation maturity assessment model, it was noticed that most institution focused their digital transformation effort in the area of enabling processes, while much less in planning and governance, learning and teaching, and research respectively (see Table II). Respondents attributed this to the availability of third party systems supporting student administration, library services, finance an accounting, etc. Ellucian and Oracle are among the main contenders in this area. Systems supporting accreditation, research, and curriculum management are relatively new in the market, compared to systems supporting enabling processes. Finally, the data findings shows clearly how critical is the role of IT governance in ensuring that all mega and major processes receive the needed support. A segmented structure of data ownership can deliver a segmented vision that can directly affect digital transformation completeness, effectiveness, and alignment.

\begin{tabular}{|c|c|c|c|c|}
\hline Less Mature & & & & More Mature \\
\hline $0 \%$ & $0 \%$ & $18 \%$ & $67 \%$ & $15 \%$ \\
\hline & \multicolumn{4}{|c|}{ No digital Initiative } \\
\hline & \multicolumn{4}{|c|}{ Desire/Ambition } \\
\hline & \multicolumn{4}{|c|}{ Designing } \\
\hline & \multicolumn{4}{|c|}{ Delivering } \\
\hline & \multicolumn{4}{|c|}{ Harvesting } \\
\hline
\end{tabular}

Fig. 4. Digital Transformation Maturity reported. 
TABLE IV. REPORTED DT MATURITY PERCEPTION BY MEGA AND MAJOR PROCESS

\begin{tabular}{|l|l|}
\hline Higher Education Mega and Major Processes & DT Maturity \\
\hline Learning and Teaching Processes & \\
\hline Study Program Accreditation) & $32 \%$ \\
\hline Teaching processes preparation and realization & $74 \%$ \\
\hline Teaching process Assessment & $22 \%$ \\
\hline Student and Teacher Mobility Realization & $38 \%$ \\
\hline Enabling Processes & \\
\hline Student Administration Services & $92 \%$ \\
\hline Library Services & $86 \%$ \\
\hline Staff provision and development services & $65 \%$ \\
\hline Finance and accounting services & $83 \%$ \\
\hline Marketing, sales, and distribution services & $56 \%$ \\
\hline Procurement services & $83 \%$ \\
\hline Research Processes & \\
\hline Research planning & $36 \%$ \\
\hline Research preparation & $32 \%$ \\
\hline research conduct & $18 \%$ \\
\hline Research outcome monitoring & $18 \%$ \\
\hline Research evaluation & $24 \%$ \\
\hline Planning and governance processes & \\
\hline Organization management services & $54 \%$ \\
\hline Change and business process management & $64 \%$ \\
\hline Plan development & $88 \%$ \\
\hline Budget and fund planning & $36 \%$ \\
\hline Performance assets & \\
\hline Higher Education Mega and Major Processes & \\
\hline & \\
\hline
\end{tabular}

TABLE V. REPORTED DT CHALLENGES IN UAE HIGHER EDUCATION

\begin{tabular}{|l|l|}
\hline Digital Transformation Challenge & Consensus \\
\hline Wholistic Vision & $76 \%$ \\
\hline Personnel Competency and IT Skills & $54 \%$ \\
\hline Data Structure, Data Processing, and Data Reporting & $52 \%$ \\
\hline Redundant Systems & $42 \%$ \\
\hline Third Party Reporting Systems & $42 \%$ \\
\hline Manual Entries (Middle Man) & $38 \%$ \\
\hline Potential Use by Customers & $28 \%$ \\
\hline Regulatory and Business Environment & $16 \%$ \\
\hline Social and Economic Impact & $12 \%$ \\
\hline Privacy and Security Concerns & $4 \%$ \\
\hline IT infrastructure & $3 \%$ \\
\hline Affordability and Budget Constraints & $2 \%$ \\
\hline Other capability constraints & $1 \%$ \\
\hline
\end{tabular}

What are the key digital transformation challenges facing the UAE examined higher education institutions?
The data findings of this study reveals a number of digital transformation challenges. While some of the reported challenges are consistent with some of the challenges reported in literature, some of the challenges listed were specific to the UAE higher education. Table $\mathrm{V}$ lists digital transformation challenges in UAE higher education, as reported by the respondents.

\section{A. Holistic Vision}

The data supported findings of this study show that the most critical challenge facing digital transformation in UAE higher education is the lack of a holistic digital transformation vision. The data reveal that none of the examined institutions had a stand-alone digital transformation vision or plan. Two public universities had list of key performance indicators to satisfy TRA requirements. Most of the other institutions worked on a list of ad-hoc automation initiatives, mainly driven by IT personnel. In several cases, redundant processes and shadow systems were identified. Some of the respondents reported confusion about digital transformation ownership. Several IT directors, chief information officers, and academic administrators did not believe that they are responsible for digital transformation. IT directors and chief information officers expected academic administrators to identify, initiate, and prioritize what processes should be digitally transformed, while academic administrators viewed digital transformation as a technical process that should be driven, initiated, and prioritized by IT directors and the chief information officers. Some of the respondents viewed digital transformation as a joint responsibility that lacks proper monitoring, initiation, and management.

\section{B. Personnel Competency and IT Skills}

The second critical challenge of digital transformation reported was the lack of critical IT skills. IT Personnel in the UAE are mainly comprised of Asian expatriates. IT personnel lack previous experience in the higher education sector, and support English-based systems, English-based curricula, and operations. Similarly, many IT managers and directors did not have prior higher education or technical experience, which is critical in establishing a holistic digital transformation vision and plan.

Respondents reported systems that were not used, while annual license is regularly paid; in-house developed systems that were redundant; IT governance, that was not established, requests for new systems driven by individuals based on familiarity; segmentally initiated digital transformation decisions; poor and underdeveloped automation efforts that did not create any real value for the institution or provide services with customer -centric view.

Given the profile of the workforce in the UAE, this digital transformation challenge is more specific to the UAE higher education environment. Experience with systems such as Banner, people soft, campus solution, etc. is more difficult to attract in the MENA region compared to the US and Europe. With few exceptions, many universities are supporting critical operations, including admission, registration, advising, scheduling, and graduation with personnel that have had no prior experience with those systems or higher education. 


\section{Data Structure, Data Processing, and Data Reporting}

The Third critical challenge reported was data structure, processing, and reporting (input-process-output). This challenge can be linked to the second reported challenge, as it is also more pertinent to the UAE higher education environment.

Because of the lack of fundamentals such as an IT strategy, IT governance, and/or data governance, data structures and key codes were not setup correctly, and key modules were not utilized. For instance, one institution used Banner Student Information Systems "SIS", but did not utilize Banner workload module. Instead built a stand-alone system to manage faculty workload. No one knew that a small number of forms need to be populated and a fully integrated module will be available in a more efficient way.

Inconsistent college codes, program codes, major codes, etc. used across different creating inconsistent data outputs that is very difficult to verify. Business rule codes were also not well defined, organizations ended up with problems in critical academic, business, and financial areas, including major out of balance issues. Data reporting relied heavily on data extraction and ad-hoc (backend) queries and reporting. System built-in reports were limited or short of customer's specific needs; keeping in mind that most systems are made to align with the US higher education environment including Ellucian, Blackboard, Leepfrog, CurriCUNET, Taskstream, Oracle, etc. This variance in input-processing-output created a major hurdle for integration, consistency, and reporting, resulting in failure to create value and enable an effective digital transformation strategy.

\section{Redundant Systems}

The fourth challenge facing higher education institutions in UAE was the existence of redundant systems. As referred to earlier, due to the lack of proper IT and data governance, several organizations did not have a proper system/software acquisition process in place, subsequently resulting in systems, functions, and data overlap and redundancy, creating major challenges for integration and data consistency, reliability, integrity, availability, timeliness, and confidentiality.

\section{E. Third-Part Reporting Systems}

The fifth challenges cited by higher education institutions attempting to digitally transform their processes was the existence of several external reporting agencies/systems that require different data sets, formats, and requirements, including different accreditation reporting systems, and other compliance reporting systems.

Several institutions felt that need to manually extract the required data from different internal systems, then format the data sets as required for reporting purposes. Microsoft Excel formatted files are widely used to support this function.

\section{F. Manual Entries (Middle Man)}

Because institutions were required to report to multiple external entities using third-party reporting systems, a lot of data extraction, data manipulation, data formatting, and data entry was taking place; in several cases the people responsible for data extractions from the organization's different systems, were completely different from those making manual entries into third party systems, potentially leading to system and data and submission errors.

\section{G. Potential use by Customer (Adoption)}

The seventh challenge facing higher education institutions in UAE was the potential use by customers. Several respondents cited resistant to change, resistant to technology, buy-in, awareness, and training as leading causes for adoption challenges. Some of the respondents stated that processes were detached from systems causing loopholes, delays, redundancy, and errors. Other respondents cited off-the shelf systems as generic, while others did not support in-house developed system by IT personnel, and viewed them as temp-cheap solutions, driven by the insecurity of IT personnel to guarantee their jobs.

\section{H. Regulatory and Business Environment}

The eighth challenge extracted from the data set was the regulatory and the business environment. Private institutions felt more at liberty than government institutions in this category. This is natural, given that government institutions receive full funding from the government, and the government audits their books. In addition, the Telecommunication Regulatory Agency TRA has its own protocols and requirements that must be observed, including what data can or cannot be on the cloud. The purchasing process in government institutions also has its own special requirements that may linger or hinder the process of acquiring certain IT assets that would support digital transformation.

\section{Social and Economic Impact}

Although was only cited by $12 \%$ of the respondents, the ninth challenge of digital transformation was concerned with the social and economic impact. Some higher education institutions reported that some of the digital transformation initiatives were not rolled out due to social concerns about how the institution will be viewed, including cases where different genders may have direct communications or use of web cams. Many institutions stressed the importance of showing respect of the UAE culture and norms as one of the main factors for attracting UAE national students.

\section{J. Privacy and Security Concerns}

Only cited by $4 \%$ of the respondents, privacy and security concerns was cited as the tenth challenge to digital transformation. Some universities did not feel that their hardware, security, and network was not ready to manage potential security threats that could come with the expansion of their digital infrastructure. 


\section{K. IT Infrastructure}

While the majority of respondents viewed their universities IT infrastructure as mature and ready to support digital transformation, $3 \%$ of the respondents expressed concerns about the full readiness of their IT infrastructure in its entirety, and reported it as the eleventh challenge.

\section{Affordability and Budget Constraints}

Surprisingly only $2 \%$ of the respondents reported affordability and budget constraints as the twelfth challenge facing digital transformation in their organizations. Understandably, those were from small private universities, not government universities.

\section{Other Capability Consraints}

The final and the thirteenth challenge reported was reported by only $1 \%$, and it was concerned with random capability reasons that were not directly identified, but simply reported as capability constraints.

The Proposed Higher Education Digital Transformation Maturity Assessment Framework: The data findings of this study shows a significant variance between the respondents' digital transformation maturity perception, and the core criteria of digital transformation maturity. Moreover, higher education is faced with a number of digital transformation challenges. A higher education digital transformation maturity assessment framework can provide higher education institutions with guidance, criteria, and an assessment of strength and weakness areas, mapped to mega and major process.

The framework proposed in this study combines the mapping of higher education processes with the digital maturity assessment framework to create an assessment framework to measure digital transformation maturity in higher education. For the sake of illustration, Fig. 5 shows an example where the framework is used with equal weight assigned to each mega process and each major processes. Institution may choose to assign different weights. The framework acts similar to a scorecard, pinpointing areas of strength and areas of weakness across each mega and major processes, and across each maturity criterion. Using the example below, it is easy to see that the research process and the teaching and learning process are the weakest in digital transformation. Users can drill down further to see that research monitoring and evaluation are among the lowest scores. Similarly, one can also see looking at the maturity requirements that vision, strategy, and processes, and controls are among the lowest criteria. The framework can help higher education institutions track their digital transformation progress and benchmark it regularly. Institution can choose to go from mega and major processes into tasks and activities if they wish to add more details.

\begin{tabular}{|c|c|c|c|c|c|c|}
\hline \multicolumn{7}{|c|}{ Digital Transformation Maturity Framework for Higher Education } \\
\hline $\begin{array}{c}\text { Higher Education Mega and Major } \\
\text { Processes }\end{array}$ & $\begin{array}{l}\text { DT Vision, strategy, } \\
\text { leadership, and } \\
\text { communication (1) }\end{array}$ & \begin{tabular}{|c|} 
DT Talent, \\
skills, and \\
knowledge (1)
\end{tabular} & $\begin{array}{c}\text { DT Processes, } \\
\text { controls, and } \\
\text { digital } \\
\text { technologies (1) }\end{array}$ & $\begin{array}{l}\text { DT Technology } \\
\text { Infrastructure } \\
\text { (1) }\end{array}$ & \begin{tabular}{|c|} 
Approach to \\
understand and \\
communciate with \\
customers (1)
\end{tabular} & \begin{tabular}{|l|} 
Total by \\
Process
\end{tabular} \\
\hline $\begin{array}{l}\text { Learningh and Teaching Processes } \\
\qquad(20)\end{array}$ & 2 & 3 & 1 & 3 & 1.5 & 10.5 \\
\hline Study Program Accreditation (5) & 0 & 0.5 & 0 & 1 & 0 & 1.5 \\
\hline $\begin{array}{c}\text { Teaching processes preperation and } \\
\text { reliazition (5) }\end{array}$ & 1 & 1 & 0.5 & 1 & 0.5 & 4 \\
\hline Teaching process Assessment (5) & 1 & 1 & 0.5 & 1 & 1 & 4.5 \\
\hline $\begin{array}{c}\text { Student and Teacher Mobility } \\
\text { Realization (5) }\end{array}$ & 0 & 0.5 & 0 & 0 & 0 & 0.5 \\
\hline Enabling Processes (30) & 4.25 & 4.75 & 4 & 5.5 & 5.5 & 24 \\
\hline Student Administration Services (5) & 0.5 & 1 & 0.5 & 1 & 1 & 4 \\
\hline Library Services (5) & 1 & 1 & 1 & 1 & 1 & 5 \\
\hline $\begin{array}{c}\text { Staff provosion and development } \\
\text { services (5) }\end{array}$ & 1 & 1 & 1 & 1 & 1 & 5 \\
\hline Finance and accounting services (5) & 1 & 1 & 1 & 1 & 1 & 5 \\
\hline $\begin{array}{l}\text { Marketing, sales, and distribution } \\
\text { services (5) }\end{array}$ & 0.25 & 0.25 & 0 & 1 & 0.5 & 2 \\
\hline Procurement services (5) & 0.5 & 0.5 & 0.5 & 0.5 & 1 & 3 \\
\hline Research Processes (25) & 1 & 1 & 1 & 2 & 3 & 8 \\
\hline Research planning (5) & 0 & 0 & 0 & 1 & 1 & 2 \\
\hline Research preperation (5) & 0.5 & 0.5 & 0.5 & 0.5 & 1 & 3 \\
\hline research conduct (5) & 0.5 & 0.5 & 0.5 & 0.5 & 1 & 3 \\
\hline Research outcome monitoring (5) & 0 & 0 & 0 & 0 & 0 & 0 \\
\hline Research evaluation (5) & 0 & 0 & 0 & 0 & 0 & 0 \\
\hline $\begin{array}{c}\text { Planning and governance processes } \\
\text { (25) }\end{array}$ & 3.5 & 3.5 & 3.5 & 3.5 & 5 & 19 \\
\hline $\begin{array}{c}\text { Organziation management services } \\
\text { (5) }\end{array}$ & 1 & 1 & 1 & 1 & 1 & 5 \\
\hline $\begin{array}{c}\text { Change and business process } \\
\text { management (5) }\end{array}$ & 0.5 & 0.5 & 0.5 & 0.5 & 1 & 3 \\
\hline Plan development (5) & 0.5 & 0.5 & 0.5 & 0.5 & 1 & 3 \\
\hline Budget and fund planning (5) & 1 & 1 & 1 & 1 & 1 & 5 \\
\hline Performance assets (5) & 0.5 & 0.5 & 0.5 & 0.5 & 1 & 3 \\
\hline Total by DT Requirement & $10.75 / 20$ & $12.25 / 20$ & $9.5 / 20$ & $14 / 20$ & $15 / 20$ & $61.5 / 100$ \\
\hline \multicolumn{7}{|l|}{ Criteria and Score guidelines } \\
\hline Desire/Ambition & 0 & & & & & \\
\hline Planning and Designing & $0.25-.49$ & & & & & \\
\hline Delivering & 0.50 .74 & & & & & \\
\hline Harvesting & $.75-100$ & & & & & \\
\hline
\end{tabular}

Fig. 5. Higher Education Digital Transformation Maturity Framework.

\section{CONCLUSION}

Digital transformation is one of the biggest catalysts of the business environment today, and higher education is not excluded from this evolution. It is a move that goes beyond the scope of systems and new technologies, while also representing the modernization of organization philosophy, purpose, competition, and patterns that change with emerging audiences. As the business environment, students, and employees change, they do so at an accelerated speed that often exceed an organization's ability to adapt. This disruption causes critical business functions and processes to inevitably be exposed within and outside the organization; subsequently requiring the restoring of new investments in technology, business models and processes to more effectively compete in a continual digital economy shift. Digital transformation is an inevitable choice for higher education institutions everywhere, especially after COVID-19. 
Digital transformation is a process that can hardly be historically compared to any other process, as it does not exclude the development levels of different countries.

In other words, all countries, regardless of their development level must undergo some level of digital transformation; and while in the developed world, the need for digital transformation has been reinforced and installed, and organizations and governments have developed sophisticated methods for applying digital technology to create products or to deliver certain services, and add value, some developing countries are still attempting to move from desire and ambition to planning, delivering and harvesting.

Despite all the talk about digital transformation in developed and developing countries, and across all industries, the reality is that digital transformation is only as useful as its rate of true implementation and return on investment. Otherwise, organizations will not benefit in terms of efficiency, effectiveness, cost-savings, competitive advantage, and decision-making.

For a number of decades, higher education institutions globally claimed digital transformation maturity, citing students' information systems, learning management systems, etc. The COVID-19 pandemic forced many institutions to use remote teaching, disrupting the regular and normal business environment and operations, subsequently exposing critical functions and their true level of digital transformation maturity and challenges.

The UAE is one of the leading developing nations in terms of IT infrastructure, and the adoption of new technologies. The UAE government has made significant leaps in e-government, e-commerce, e-business, and e-services in general. There are several agencies contributing to this advancement, including the Ministry of Artificial Intelligence, Smart Dubai, and the Telecommunication Regulatory Authority.

Given the importance of digital transformation, higher education, and the role they both play in today's digital/knowledge economy, the aim of this study is to examine the digital transformation maturity level and challenges in UAE higher education institutions in the after math of COVID19, and the need to provide remote e-service to students, employees, and other customers and stakeholders.

The first research question is concerned with measuring the level of digital transformation maturity in UAE higher education institution using Deloitte's digital maturity assessment framework, and Pekovitcs mega and major processes mapping. The data findings reveal a major variance between the perception and the requirements of digital transformation maturity. The examined institutions did not have a digital transformation vision, leadership, strategy, plan, champions, processes, controls, approach, communication, or proper return on investment. Many of the examined institutions viewed their maturity level at delivering and harvesting, when in fact they were at either designing or ambition.

In addition, digital transformation was more evident in enabling processes such as student administration services, library services, finance and accounting, but not as much in learning and teaching, research processes, and planning and governance processes.

The second research question is concerned with the digital transformation challenges. Leading challenges reported included challenges with holistic vision; personnel competency and IT skills; data structure, data processing, and data reporting; redundant systems; third party reporting systems; manual entries; and potential use by customers.

The challenges cited by the respondents in this study are not mutual exclusive; in fact, they are interrelated in multiple ways. While some of the challenges are more critical than others, the combination of those challenges create an environment that hinders digital transformation and business success by creating dependency, timeliness, integrity, availability, cost, efficiency, effectiveness, and integration issues.

\section{RECOMMENDATIONS}

Digital transformation in education is inevitable. Higher education institutions should establish a clear vision, policies, strategies, and plans to support mature digital transformation. Institutions should communicate such policies, strategies, and vision, and receive feedback from internal and external customers and stakeholders about business process engineering and return on investment. Such plans should regularly be evaluated. Institutions should hire digital transformation experts in order to align the business strategy with digital transformation. Digital transformation should not be just another task handed down to IT personnel, or segmented among data owners. The difference between automation and digital transformation should be communicated, and training and awareness should be provided. A corner stone to all of this is to show solid management support to combat resistance to change and resistance to technology, and communicate the long term value gained from digital transformation. Digital transformation should be extended beyond the enabling processes to teaching and learning, governance, and research. Specifically, the areas of course, program, and student assessment and evaluation. The proposed framework of this study can be used as a scorecard to assess the digital transformation maturity in higher education, assisting institutions in pinpointing processes and criteria that require further attention.

\section{REFERENCES}

[1] Al Tamimi \& Company, report on "Digital Transformation in the Education Space: A Review of the Impact of New Technologies on Middle East Education”, 2019.

[2] A. Bayler, and O. Oz, “Academicians' Views on Digital Transformation in Education. International Online Journal of Education and Teaching (IOJET) 2018, 5(4), 809-830.

[3] Bounfour, A. "From IT to Digital Transformation: A Long Term Perspective. Digital Future and Digital Transformation. 2020.

[4] D. Chaurasiya, "Digital Transformation: A Case Study", retrieved from https://www.researchgate.net/publication/340385414_Digital_Transform ation?enrichId=rgreq-e65c791fef $4 \mathrm{fde} 3 \mathrm{c} 103 \mathrm{a} 4370994 \mathrm{ad} 74 \mathrm{e}-$

XXX\&enrichSource $=$ Y292ZXJQYWdlOzM0MDM4NTQxNDtBUzo4 NzU4ODQyMzE3OTA1OTNAMTU4NTgzODQ4MjI1MA\%3D\%3D\& el=1_x_2\&_esc=publicationCoverPdf, 2020.

[5] Deloitte Digital. The journey to government's digital transformation Report. 2019. 
[6] M. H. Ismail, M. Khater, M. Zaki, "Digital Business Transformation and Strategy: What do we know so far?", 2017. Retrived from https://cambridgeservicealliance.eng.cam.ac.uk/resources/Downloads/M onthly\%20Papers/2017 NovPaper_Mariam.pdf.

[7] Gartner, Inc.'s free "Creating Digital Value at Scale" webinar is a special report based on the opening keynote of the 2017 Gartner Symposium.

[8] E. Göll and J. Zwiers, "Technological Trends In The Mena Region: The Cases Of Digitalization And Information and Communications Technology (Ict), MENARA, 2018.

[9] Y. Limani, E. Hajrizi, L. Stapleton, M. Retkoceri, "Digital Transformation Readiness in Higher Education Institutions (HEI): The Case of Kosovo", Science Direct, IFAC PapersOnLine 52-25 (2019).

[10] C. Mahlow, and A. Hediger, "Digital Transformation in Higher Education-Buzzword or Opportunity?". Special Issue: Paradigm Shifts in Global Higher Education and eLearning. MAY 2019.

[11] V. Maltese, "Digital Transformation Challenges for Universities: Ensuring Information Consistency Across Digital Services". Journal of Cataloging and Classification Quarterly. Volume 56, 2018 - Issue 7. 2018.

[12] A. Marks, M. Alali, K. Reitesema, "Learning Management Systems: a shift Toward Learning and Academic Analytics". International Journal on Emerging Technologies in Learning. (2016).

[13] Digital McKinsey, "Digital Middle East: Transforming the region into a leading digital economy". Mckinsey, 2016.

[14] NV. "Digital Transformation in Higher Education. [Online] Navitas Ventures. Available: https://www.navitasventures.com/wp-content/ uploads/2017/08/HE-Digital-Transformation-Navitas_Ventures_EN.pdf. 2017.

[15] A. Norton, s. Shroff, and N. Edwards, "Digital Trasnformation: An Enterprise Architecture Prespective", Publish Nation Limited, UK, 2020.

[16] The Organisation for Economic Co-operation and Development OECD (2016). Digital Government Strategies for Transforming Public Services in the Welfare Areas.[Online] http://www.oecd.org/gov/digitalgovernment/Digital-Government-Strategies-Welfare-Service.pdf.
[17] B. Parlak, "Dijital çağda eğitim: Olanaklar ve uygulamalar üzerine bir analiz [Education in Digital Age: An analysis on opportunities and practices], Süleyman Demirel University, Journal of Faculty of Economics and Administrative Sciences, 22(15), 1741-1759. 2017.

[18] I. Petkovics, P. Tumbas, P. Matkovic, Z. Baracskai, "Cloud Computing Support to University Business Processes in External Collaboration". Acta Polytechnica Hungarica, vol.11, no.3, pp.181-200, 2014.

[19] K. Sandkuhl, H. Lehmann, "Digital Transformation in Higher Education - The Role of Enterprise Architectures and Portals", Digital Enterprise Computing (DEC 2017), 2017.

[20] K. Schwab, K. Dördüncü sanayi devrimi [Fourth industrial revolution], İstanbul: Optimist Publications. 2016.

[21] K. Schwertner, "Digital transformation of business". Trakia Journal of Science, 15(Suppl.1), pp.388-393. 2017.

[22] L. Seres, V. Pavlicevic, P. Tumbas, "Proceedings of INTED2018 Conference". 5th-7th March 2018, Valencia, Spain.

[23] B. Solis, "8 Success Factors of Digital Transformation" Altimeter. Prophet Thinking. [online]: https://www.prophet.com/thinking/2016/02 /brief-the-opposite-approach-8-success-factors-of-digitaltransformation/.

[24] J. Thompson, "Books in the Digital Age". New York, NY: John Wiley \& Sons. 2013.

[25] A. Yıldırım, \& H. Simșek, "Sosyal bilimlerde nitel araștırma yöntemleri [Qualitative research methods in the social sciences". Ankara: Seçkin Publishing.2013.

[26] R. Walker, J, Voce, J. \& M, Jenkins, "Charting the development of technology-enhanced learning developments across the UK higher education sector: A longitudinal perspective" (2001-2012). Interactive Learning Environments, 24 (3), 438-455. doi:10.1080/10494820.2013. 867888, 2016.

[27] J. Xiao, "Digital transformation in higher education: critiquing the fiveyear development plans (2016-2020) of 75 Chinese universities", Distance Education, 40:4, 515-533, DOI: 10.1080/01587919.2019. $1680272,2019$. 